\title{
The Association Between Exposure to Environmental Tobacco Smoke (ETS) in Mother During Pregnancy with Low Birth Weight (LBW) Infants
}

\author{
Rusnani binti Ab Latif \\ Kubang Kerian Nursing College \\ 16150, Kubang Kerian, Kelantan, Malaysia \\ Correspondence E-mail: rusnani.adnan@yahoo.com
}

\begin{abstract}
Introduction: Low birth weight (LBW) is a major contributing factor towards high infant mortality in developing countries. One of the most predominant causes of LBW is the mother's access to prenatal care; however exposure to environmental tobacco smoke (passive smoking) may have a modest adverse effect on birth weight.

Methodology: Two-hundred thirty postnatal mothers were participated as respondents in this study. A self-administered questionnaire was used. Data was collected by interviewing the postnatal mothers. A One Way Analyses Of Variance (ANOVA) and Chi-Square test were used. The differences were evaluated significant at $p<0.05$.

Results: There was highly significant association between mother's exposure to environmental tobacco smoke (ETS) or passive smoking with birth weight $(F=15.200, p=0.000)$. There is a significant association between the number of cigarettes per day father's smoke with birth weight $(F=4.970, p=0.003)$. However, analysis by using Chi-Square shows that the exposure of smoke to other family members was not statistically significant $\left(X^{2}=1.68, p=0.431\right)$.

Conclusion: Therefore, the improved quality of antenatal care can reduce health complications with subsequent improvement in birth weight. On the other hand, early antenatal care is crucial to favorable pregnancy outcome.
\end{abstract}

Keywords: Environmental tobacco smoke (ETS), Pregnancy mothers, Low Birth Weight (LBW)

\section{Introduction}

Birth weight is a powerful predictor of infant growth and survival. In Malaysia (1984) reported incidence of LBW (Low Birth Weight) infants were $10 \%$ and the prevalence studies on LBW infants delivered in Hospital Universiti Sains Malaysia, Kelantan showed a rate of 6.3 $\%$ (Siti Arbaiyah et al., 1999). The highest incidence of LBW occurs in the sub region of South-Central Asia, where 27 per cent of infants are LBW (The United Nations Children's Fund and World Health
Organization, 2004). The goal of reducing low birth weight incidence by at least one third between 2000 and 2010 is one of the major goals in 'A World Fit for Children,' the Declaration and Plan of Action adopted at the United Nations General Assembly Special Session on Children in 2002 (The United Nations Children's Fund and World Health Organization, 2004).

Risk factors associated with pre-term birth includes cigarette smoking during pregnancy, 
prior pre-term birth, low pre-pregnancy weight, and maternal chronic diseases. The biological process that affect the fetus in uterus are related to the mother's physiology, including her nutrition mother's weight before pregnancy and history of having newborns with LBW, exercise, infections, and consumption of tobacco, alcohol and other drugs (Lynch \& Kaplan, 2000). According to Djauzi (2005) the influence of smoking on pregnancy is very serious. Cigarettes can reduce blood flow to the placenta so the risk of inflicting impaired fetal growth. Cigarettes can also increase the risk miscarriage, low infant weight and respiratory tract disorders baby.

\section{Objective}

To determine the association between smoking exposure to environmental tobacco smoke (ETS) in mother during pregnancy with Low Birth Weight (LBW) infants.

\section{Literature Review}

\section{Low birth weight (LBW)}

The finding of the previous study by Arifeen (1997) shown that about $80 \%$ of all affected newborns with LBW are born in Asia. According to Goldenberg and Rouse (1998), on average the worldwide incidence of LBW is $17 \%$ per year, making LBW an important infant health problem in many populations. Morris et al. (1999) study reported that the average incidence of LBW in developing countries to be $17 \%$ of all live births. The third target of World Health Organization (WHO) document "Health for All in $21^{\text {st }}$ Century" has stated that "by the year 2020 all newborn babies, infants and preschool children in the region should have better health, ensuring a healthy start in life". The primary objective for the implementation of this target is to reduce the number of infants born below 2500 gram (WHO Regional Office for Europe, 1998).

LBW babies $(<2500 \mathrm{~g})$ contribute to majority $(65-70 \%)$ of the neonatal mortality (United Nations Children's Fund and World Health Organization 2004; Nair, 2001). LBW refers only to infants born weighing less than $2500 \mathrm{~g}$, regardless of gestational age and the cause of
LBW (WHO, 1992). Three categories that can be distinguished are as follows: Premature or preterm LBW babies (born before 37 complete weeks of gestation or with fewer than 259 days of gestation); term LBW, that is, born between 37 and 42 complete weeks of gestation, or between 259 and 293 days of gestation and Post term LBW, born after 42 weeks or 294 days of gestation. LBW infants can be further classified as "very low birth weight" (1000-1499 g) and "extremely low birth weight" (500-999 g). LBW are mainly related to uterus-placental insufficiency and poor energy substrate transfer, resulting in neonatal complications like birth asphyxia, hypothermia, meconium aspiration, polycythaemia, hypoglycemia, hypocalcemia and thrombocythaemia.

\section{Association between smoking habits and LBW}

Maternal smoking in pregnancy is associated with adverse pregnancy outcomes, including an increased risk for pre-term birth, placental abruption, placenta previa, and low birth weight (Burguet et al., 2004). Some studies have been conducted based on the influence of tobacco smoke on birth weight. Smoking pregnant women have been associated with numerous pregnancy and fetal outcomes. Second, hand smoke also adds a risk to pregnancy. Exposure to environmental tobacco smoke (passive smoking) may have a modest adverse effect on birth weight. There is increased risk of ectopic pregnancy as well as spontaneous abortion, placenta previa, premature rupture of the membranes pre-term delivery. The babies delivered have higher risks of perinatal mortality, sudden infant death syndrome and LBW.

According to Lightwood et al. (1999), concluded that an annual decrease of $1 \%$ of the prevalence of smoking among pregnant women, over a period of 7 years, would reduce the number of LBW infants by 57000 and would save RM 572 million. Smoking has been implicated in the etiology of abruption placenta, placenta previa, spontaneous abortion, premature delivery, and stillbirth. Intrauterine growth retardation is the most strongly documented adverse effect of smoking during pregnancy. 
Smoking cessation in pregnancy is strongly affected by socio-economic status(SES), with women of lower education, income and employment status far more likely to continue smoking than women from higher SES groups (Graham \& Der, 1999). Similar finding by Lumley (2001), found that despite extensive knowledge about lower rates of cessation and higher rates of low birth weight among lower SES women, review level evidence does not address the features of effective interventions that might increase smoking cessation in these groups.

Study done by Magee, Hattis \& Kivel (2004), reported that when stratifying for the effect of smoking, the rate of LBW was $6.38 \%$ among nonsmokers, 9.5\% (RR 1.48, 1.38-1.61) among light smokers, $11.67 \%$ (RR 1.82, 1.632.05) among moderate smokers and $11.72 \%$ (RR 1.84, 1.33-2.54) among heavy smokers. Sixty percent of the overall population effect of smoking on LBW was in the category of light smokers. This study shows that the amount of LBW attributable to smoking was $6.4 \%$ in this sample. Among those who smoked, LBW was $58 \%$ more likely than among nonsmokers, and $60 \%$ of the overall population effect of smoking on LBW was noted among light smokers.

\section{Methodology}

This study was carried out in Hospital Tumpat, Kelantan. Universal sampling method was used where all infants who fulfill inclusion criteria selected. The sample size was 230 infants. It based on Department Statistic Malaysia about Crude Birth Rate (2007), proportion birth rate is $18.0 \%$. Statistical Package for Social Sciences (SPSS) version 16 for Windows was used. Descriptive statistics were applied to compute the mean, frequency, standard deviation and other measures of central tendency. A One Way Analyses of Variance (ANOVA) and ChiSquare test were use. Statistically significant data were considered to be those had a $p$ value $<0.05$.

\section{Study ethics}

Before carrying out this research project, an approval letter was sent to the Hospital Tumpat administration to get the consent. The researcher explained the aim and procedure of study to the respondents. The researcher also explained to the respondents that their answers were confidential and only used for the purpose of academic research. Written informed consent of all participants was being acquired.

\section{Results}

Table I showed the distribution of respondents on exposure tobacco smoke. All the respondents were non-smoker. Result showed that there were $125(54.3 \%)$ husband smoke, $101(43.9 \%)$ non-smoker and only $4(1.7 \%)$ were past smoking but stopped.

Table I: Distribution of respondents on exposure tobacco smoke (ETS) (N=230)

\begin{tabular}{|c|c|c|}
\hline Variables & $\mathrm{n}$ & Percentage (\%) \\
\hline \multicolumn{3}{|l|}{ Mother's smoking } \\
\hline Yes & - & \\
\hline No & 100 & 100 \\
\hline \multicolumn{3}{|l|}{ Father's smoke } \\
\hline Yes & 125 & 54.3 \\
\hline No & 101 & 43.9 \\
\hline Past smoking but stopped & 4 & 1.7 \\
\hline \multicolumn{3}{|l|}{$\begin{array}{l}\text { Cigarettes per day does he } \\
\text { smoke }\end{array}$} \\
\hline $1-4$ cigarettes & 51 & 22.2 \\
\hline 5-9 cigarettes & 56 & 24.3 \\
\hline $10-14$ cigarettes & 16 & 7.0 \\
\hline$>14$ cigarettes & 2 & 0.9 \\
\hline Total & 125 & 54.3 \\
\hline \multicolumn{3}{|l|}{ Exposure to other family } \\
\hline \#Yes & 36 & 15.7 \\
\hline No & 194 & 84.3 \\
\hline
\end{tabular}

\# Cigarettes smoked by father, father in law, brother- in law. 


\section{Association between maternal exposure to tobacco smoke (ETS) and birth weight}

Table II shows the association between maternal exposed tobacco smokes and birth weight. In this study, all the respondents were non-smoker. The mean birth weight of smoking by father were lowest (2957.24 \pm 342.29$)$ compared to the nonsmoking father (3235.14 \pm 411.12$)$. There was statistically significant association between father's smoke with birth weight $(F=15.200, p$ $=0.00$ ). The number of cigarettes per day father's smoke were also statistically significant $(F=4.970, p=0.003)$. However, analysis by using Chi-Square shows that the exposure of smoke to other family members was not statistically significant $\left(x^{2}=1.68, p=\right.$ $0.431)$.

Table II: The association between maternal exposed tobacco smokes and birth weight $(n=230)$

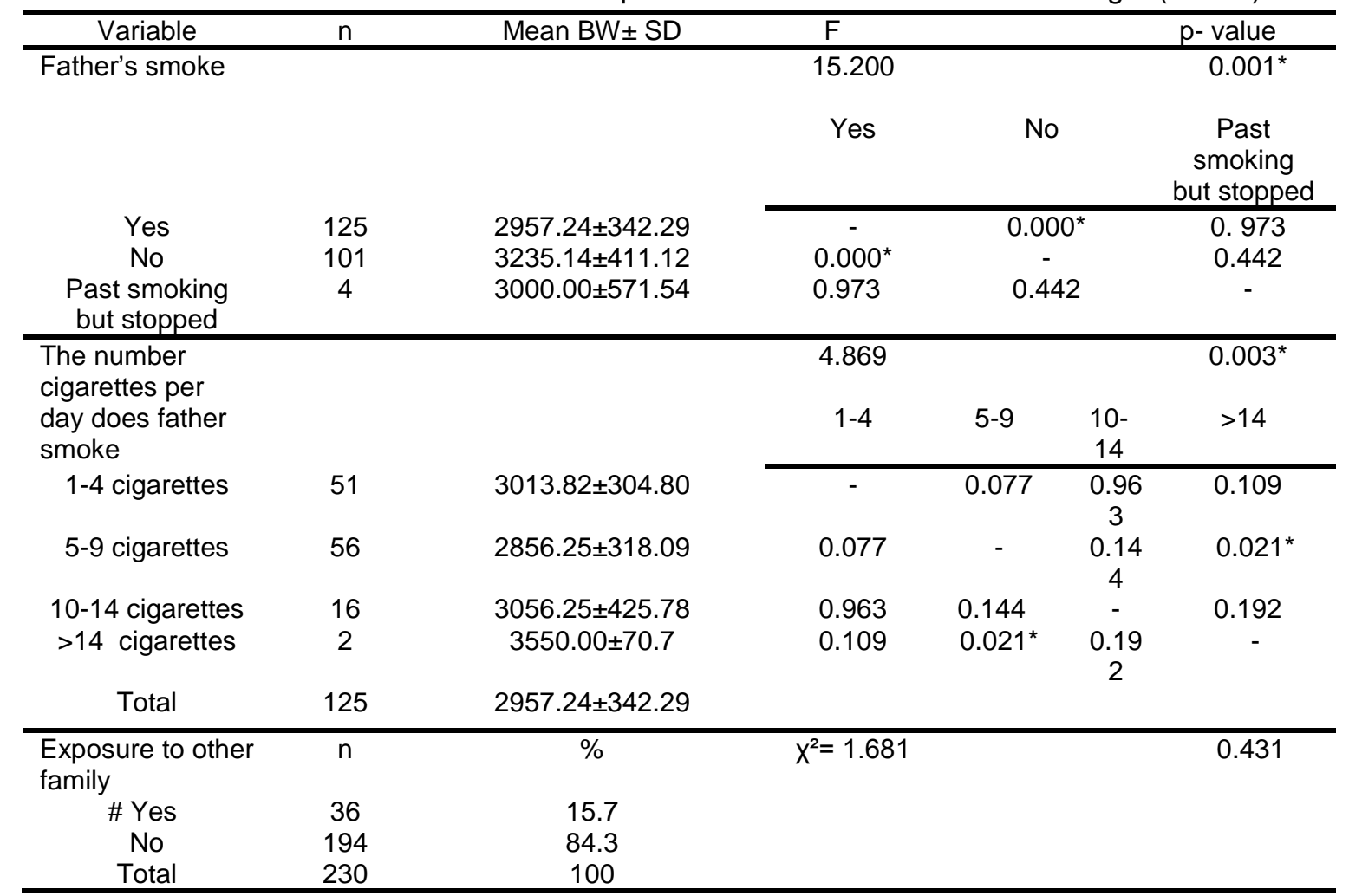

\# Cigarettes smoked by father, father in law, brother in law.

* Significant $p<0.05$

Tukey Post hoc shows maternal exposed tobacco smokes was significantly different from non-maternal exposed tobacco smokes $(p<0.05)$ and the number of cigarettes per day father smoke group 5-9 cigarettes was significantly different from group $>14$ cigarettes per day $(p<0.05)$.

\section{Discussion}

Second hand smoke also adds a risk to pregnancy. Exposure to environmental tobacco smoke (passive smoking) may have a modest adverse effect on birth weight. In this study, all the mothers were non-smoker, however, this study found that there was highly significant associations between mother's exposure to environmental tobacco smoke (ETS) or passive smoking with birth weight $(F=15.200, p=0.001)$. It also found that there was a significant association between the number cigarettes per day does husband smoke with birth weight $(F=4.970, p$ $=0.003$ ).

Bernstein, Mongeon, Badger, Solomon, Heil, Higgins (2005), reported that maternal smoking during the third trimester was the strongest predictor of birth weight after adjusting for gestational age. Each cigarette 
smoked per day during the third trimester is estimated to contribute to a $27-\mathrm{g}$ reduction in the birth weight of the infant. Maternal smoking affects the fetus during all stages of pregnancy, the most significant effect on the birth weight of the off spring occurs during late pregnancy, especially in the case of mothers who are heavy smokers (>8-10 cigarettes/day) (Horta, et al.1997; Jaddoe et al .2008).

This is consistent with Goel et al. (2004) study. The study was proven that, exposure to environmental tobacco smoke (ETS) during pregnancy was significantly associated with a higher risk of small for gestational babies during the antenatal period. There is a significant between the reduction in tobacco use will increases the birth weight, hence decreases the incidence of LBW. It is supported by Spravue et al. (1999) in their study, reported that the interaction between maternal smoking and pregnancy outcomes, seft reported maternal smoking during the second trimester is associated with fetal growth restrictions in a dose response manner.

According to Kramer et al. (2000), from their analysis found that for effective public health intervention in relation to the prevention of low birth weight are interventions to promote smoking cessation and nutrition intervention among pregnant mother. Smoking is the major modifiable risk factor that contibutes to low birth weight. Babies born to women who smoke weight on average $200 \mathrm{~g}$ less than babies born to non-smokers. It is supported by Messecar (2001) study. It found that the incidence of low birth weight is twice as high among smokers as non-smokers. During the antenatal period, a study showed that exposure to environmental tobacco smoke (ETS), during pregnancy was significantly associated with a higher risk of small for gestational babies (Goel et al., 2004). According to Djauzi's opinion (2005) the influence of cigarettes on pregnancy is very serious. Cigarettes can reduce blood flow to placenta so risky against interference growth of the fetus. Cigarettes can increase risk miscarriage, low infant weight and respiratory tract disorders baby.
Furthermore, the carbon monoxide effect contained in cigarette smoke will disrupt the distribution of nutrients and oxygen to the fetus (Oktavianis, 2011). In addition to carbon monoxide, the resulting nicotine of cigarette smoke active smokers then inhaled by pregnant women also can decrease perfusion placenta. Nicotine coming in into the mother's blood can pass through placenta and some affect organs of the fetus the influence of these substances is baby growth below normal. Nicotine, the most important component of tobacco, is present in the placenta at $15 \%$ higher concentration than in maternal blood. Nicotine causes uterine vasoconstriction by inducing maternal catecholamine release (Lambers, D.S., \& Clark, 1996).

\section{Conclusion}

Prevention of LBW and other adverse birth outcomes have for years focused only on prenatal care. It is because one of the most predominant causes of LBW is the mother's access to prenatal care. However quality prenatal care is still crucial to improve birth outcomes, if the mothers during pregnancy exposure to environmental tobacco smoke (ETS). It is now clear that prenatal care alone is not sufficient.

On the other hand, early antenatal care is crucial to favorable pregnancy outcome. All pregnant women should be encouraged to enter prenatal care early in their pregnancies to facilitate early identification of risk factors, whereby, all pregnant women should be assessed during their first prenatal care visit to identify risks for adverse pregnancy outcome, including health history, pregnancy history, nutritional status, screening for alcohol, tobacco and other drug use, psychosocial history, including stress, depression, anxiety, and domestic violence. Therefore, women at high risk for low birth weight need close monitoring and tracking by a qualified prenatal care provider with possible referral to a high risk obstetrical specialist and /or referral for case management and social support. 


\section{Acknowledgment}

This research is self-funded and did not receive any grant from funding agencies be it

\section{References}

Arifeen, S. E. (1997). Birth weight intrauterine growth retardation and prematurity: prospective study of infant growth and survival in the slums of Dhaka, Bangladesh. Doctor of Public Health dissertation, Johns Hopkins University, Baltimore.

Bernstein, I. M., Mongeon, J.A., Badger, G.J., Solomon, L., Heil, S.H.,\& Higgins, S.T.(2005). Maternal smoking and its association with birth weight. Obstet Gynecol, 106, 986-991.

Burguet, A., Karminski, M., Abraham- Lerut, L., Schaal, J. P., Combonie, G., Fresson, J., et al. (2004). The complex relationship between smoking and very preterm delivery: Results of the Epipage study. BJOG. 111, 258-65.

Department Statistic Malaysia Crude Birth Rate (2007). www. indexmundi.com

Djauzi, S. (2005). Panduan Hidup Sihat, dari Soal Pemeriksaan Kesihatan Sampai Vertigo, Jakarta. Kompas.

Goel, P., Radotra, A., Sing, I. (2004). Effects of passive smoking on outcomes in pregnancy. J Post Grad Med Obstet Gyneacol, 50,12-16.

Goldenberg, R. L., \& Rouse, D. J. (1998). Prevention of premature birth. New England Journal of Medicine, 339, 313-320.

Graham, H., \& Der, G. (1999). Patterns and predictors of smoking cessation among British women. Health Promotion International, 14, 231-9.

Jaddoe, V. W., Troe, E. J., Hofman, A., Mackenbach, J.P., Moll, H.A., Steegers, E.A., et al.(2008). Active and passive maternal smoking during pregnancy and the risks of low birth weight and preterm birth: the Generation $\mathrm{R}$ Study. Paediatric and Perinatal Epidemiology, 22, 162-171. from the public, commercial or not-for-profitsectors.

Kramer, M. S., Seguin, L., Lydon, J., \& Goulet, L.(2000). Socio- economic disparities in pregnancy outcome: why do the poor fare so poorly? Paediatric and Perinatal Epidemiology. 14, 194-210.

Lambers, D.S., \& Clark, K.E. (1996). The maternal and fetal physiologic effects of nicotine. Semin Perinatol. 20, 115-126.

Lightwood, J. M., Phibbs, C.S., Glantz, S.A.( 1999). Short term health and economic benefits of smoking cessation; low birth weight. Pediatric Journal. 104(6), 1312.

Lumley, J., Oliver, S., \& Waters, E. (2001). Interventions for promoting smoking cessation during pregnancy (Cochrane Rewiew). In: The Cochrane Library, Issue 3. Oxford: Update Software.

Lynch, J., Kaplan, G. (2000). Socioeconomic Position. In Social epidemiology. Oxford University Press. 13 -35.

Magee, B. D, Hattis, D, Kivel, N. M. (2004). Role of smoking in low birth weight. $J$ Reprod Med. 49(1), 23-7.

Messecar, D. (2001) .Smoking cessation interventions for pregnant women. Journal of Academic of Nurse Practitioners. 3, 171-7.

Morris, S. S., Grantharm- McGregor, S. M., Lira, P.I., Assucao Am, Ashworth, A.(1999). Effects of breastfeeding and morbidity on the development of low birth weight term babies in Brazil. Acta Paediatrics. 88(10), 1101-6.

Nair, M. K. C. (2001). Child Development 2000 and Beyond. Bangalore: Prism Books Private Limited, 40-49.

Oktavianis.(2011). Efek Pemberian Asap Rokok terhadap Kehamilan Tikus Putih(Rattus Norvegicus). Tesis Padang. Program Studi IImu Biomedik, Universitas Andalas Padang. 
Siti Arbaiyah, et al. (1999). Risk factors for term small for gestational age babies in HUSM Dissertation. Submitted for Partial Fulfillment of The Requirement for degree of Master of Medicine (Paediatrics) USM.

Sprauve, M. E., Lindsay, M.K., Drews- Botsch, C.D., Graves, W. (1999). Racial patterns in the effect of tobacco use on fetal growth. American Journal: Obstetrician and Gynecology.181 (1), 22-7.

United Nations Children's Fund and World Health Organization. (2004). Low Birth weight: Country, regional and global estimates. UNICEF, New York.
World Health Organization (WHO). (1992). International Statistical Classification of diseases and related health problem, tenth revisions, World Health Organization, Geneva.

WHO Regional Office for Europe. (1998). Health in Europe. (1997). Copenhagen, WHO Regional Office for Europe (WHO Regional Publications, European Series, No. 83). 